\title{
ANÁLISE DA VIABILIDADE ECONÔMICA FINANCEIRA PARA O INVESTIMENTO DE UM APLICATIVO DE EMPRÉSTIMOS DE CAPITAL COM BASE EM INDICADORES FINANCEIROS
}

\author{
Ana Carolina do Nascimento Frederico (UFC) ana.carolina.nascimento@ hotmail.com \\ Cibele Maria de Sousa (UFC) sousah.cibele@gmail.com \\ Nágila Oliveira Barbosa (UFC) nagila_b@hotmail.com \\ Maxweel Veras Rodrigues (UFC) maxweelveras@gmail.com
}

\section{Resumo}

O ambiente corporativo está cada vez mais competitivo, motivando as empresas a procurar oferecer produtos e/ou serviços diferenciados para sobreviver no mercado em que atuam. Um dos fatores principais para manter-se competitivo no mercado é ter um produto economicamente saudável. Neste contexto, a análise econômica de investimentos possibilita visualizar um projeto de investimento, verificar se o projeto será viável e tempo de retorno. Desta forma, o presente trabalho tem com o objetivo verificar a viabilidade econômica de um investimento para a criação de um aplicativo de empréstimo de dinheiro para pessoa física. $\mathrm{O}$ estudo é descritivo de caráter quantitativo por meio de dados colhidos com os investidores. A empresa tem uma proposta de investir R \$ 150.000 na concretização do aplicativo Finances Happy, pois é uma ideia inovadora de emprestar dinheiro para pessoas físicas com taxas de juros menores que as do mercado, portanto a organização percebe um grande nicho de mercado. Para certificar-se se o projeto será viável, foram verificados os custos fixos baseados em aluguel, energia elétrica, mão-de-obra e internet. Os resultados mostram que: o valor presente líquido é de $\mathrm{R} \$ 222.975$, a taxa interna de retorno é de $\mathrm{R} \$ 38,96 \%$ a.a.; e o payback simples revela um tempo de recuperação de 2,47 anos (aproximadamente 30 meses). Concluise que o projeto de investimento é viável e que resultará em uma ótima projeção de lucro para a empresa.

Palavras-chave: Aplicativo. Investimento. Viabilidade Econômica

\section{Introdução}


O uso da técnica do Payback será utilizado neste estudo de caso juntamente com a ferramenta de análise de fluxo de caixa simples ou incremental, dependendo do tipo de Payback utilizado, para analisar em quanto tempo os serviços prestados pela organização, ou a sua produção, consegue retornar um dado investimento inicial.

Será observado a empresa AppMais, que desenvolve aplicações web e mobile próprias e também para terceiros.

Para que se consiga encontrar os valores corretos do Payback Simples e Descontado torna-se crucial o uso do fluxo de caixa, uma ferramenta de análise financeira usada para averiguar as entradas e saídas de caixa do empreendimento, de forma a distinguir os ativos e passivos da empresa e constatar se de fato está acontecendo lucro ou prejuízo.

Na empresa AppMais são formulados vários aplicativos por mês de acordo com a necessidade e os pedidos dos clientes, onde cada cliente passa a pagar uma mensalidade fixa. Porém analisaremos um aplicativo chamado Finances Happy, criado pela AppMais para ajudar alguns usuários a realizar empréstimos com empresas simples de crédito que fornecem esse tipo de serviço a uma taxa menor que a do mercado. No entanto não focaremos na rentabilidade dos empréstimos e sim na venda do aplicativo, em contra partida com seus gastos e custos iniciais para se ter uma noção de em quanto tempo ocorrerá o retorno desse investimento para a organização.

\section{Referencial Teórico}

\subsection{Análise Econômico Financeiro}

A Engenharia Econômica é umas das interfaces da Engenharia de Produção e, consiste em métodos e ferramentas com a função de analisar e comparar valores de investimentos necessários para começar projetos com receitas líquidas esperadas durante a vida útil do investimento. Essa análise começa na própria definição do projeto, pois a base para a tomada de decisão, ao escolher o produto ou serviço para ser desenvolvido, é a análise da viabilidade econômico-financeira de seu projeto. Esta é realizada com os dados disponíveis previamente no início do projeto, ou seja, a estimativa de orçamentos para o projeto serve para calcular o preço final do produto, que o tornaria viável e cobriria os custos envolvidos. Logo, fazer um estudo prévio da viabilidade econômico-financeira de um projeto permite o melhor desempenho do capital investido. 
Após tomar a decisão inicial, à medida que o projeto segue existe a necessidade de tomar novas decisões e até mesmo uma revisão do projeto em andamento para verificar se o mesmo continua economicamente viável, dessa forma a análise econômica também serve para monitorar o processo, para que durante o processo de desenvolvimento as decisões sejam tomadas com o mínimo de incerteza.

Para auxiliar na tomada de decisão, usam-se indicadores financeiros, para realizar a gestão econômica do projeto, e ademais é necessário fazer um fluxo de caixa esperado para o produto/serviço. Logo, a referência inicial para passar para as fases seguintes são os resultados desses indicadores tornando-se um dos critérios mais importantes para manter a decisão de executar o projeto.

\subsection{Indicadores financeiros}

Chiavenato e Cerqueira Neto (2003) afirmam que toda organização deve ser transparente e clara com seus usuários. A partir disto, as empresas precisam adotar indicadores que permitam demonstrar os resultados de forma objetiva, de maneira a auxiliar na formação de opinião pública, tanto interna como externa à entidade.

Seja qual for o tipo de investimento, é necessário ter indicadores para avaliar se o projeto trará lucro ou prejuízo. Há diferentes parâmetros para examinar um investimento. Os indicadores de análise de investimentos abordados foram: Taxa Mínima de Atratividade (TMA), Valor Presente Líquido (VPL), Taxa Interna de Retorno (TIR) e Tempo de Recuperação do Capital (Payback).

\subsection{Fluxo de Caixa}

Fluxo de caixa é uma série de pagamentos e recebimentos de dinheiro, distribuídos ao longo de um determinado tempo.

Todo investimento, independente do seu tamanho, necessita apresentar um estudo de viabilidade econômico-financeira e para respaldá-lo é importante a criação de um fluxo de caixa do projeto. Logo, o fluxo de caixa é criado em cima dos valores de entradas e saídas de recursos financeiros. 


\subsection{Valor Presente Líquido (VPL)}

O Valor Presente Líquido (VPL) é a metodologia utilizada para medir o acréscimo, ou incremento, de riqueza propiciada pela implantação de um projeto de investimento. Serve para estimar a atratividade do investimento através de equação matemática que possibilita calcular pagamentos futuros no valor presente.

Esta ferramenta tem o objetivo de estipular um valor no momento inicial, a partir de um fluxo de caixa existente de uma série de entradas e saídas. Segundo Ehrlich e Moraes (2005, pág. 21):

O método do Valor Presente Líquido consiste em colapsar todos os valores para o ponto $\mathrm{t}=0$. Dadas diversas alternativas, é possível calcular os valores atuais equivalentes às séries correspondentes e compará-los para decidir qual a melhor.

Matematicamente, o VPL pode ser identificado a partir da aplicação da equação abaixo.

$$
\mathrm{VPL}=\sum_{t=0}^{n} \frac{F C_{t}}{(1+i)^{t}}
$$

Sendo:

$F C_{t:}$ Fluxo de caixa no tempo t;

n: quantidade total de períodos na linha de tempo do fluxo de caixa;

i: taxa de juros a ser usada para descontar o fluxo de caixa.

Situações ao se analisar pela metodologia do VPL:

Se o VPL apresentar valor positivo, assim as receitas são superiores as despesas e o projeto são viáveis.

Se o VPL apresentar valor negativo, as receitas são inferiores as despesas tornando o projeto inviável.

Se o VPL for igual a zero, as receitas igualam-se as despesas, sendo assim não se obtém nem lucros e nem prejuízos. 


\subsection{Tempo de Recuperação do Capital (Payback)}

O Payback é uma ferramenta da matemática financeira também muito utilizada na tomada de decisão quando se vai investir em algo, pois a partir dela é possível calcular o período de tempo que levará para o investidor receber de volta o capital investido no projeto. Esse tempo de retorno é determinado a partir do cálculo dos lucros obtidos em cada período. Dessa forma, os investimentos preferíveis são os que possuem menor payback e para o projeto ser aceito o payback deve ser inferior ou igual ao período de tempo máximo esperado pela empresa para obter retorno sobre o seu investimento.

$$
\text { Payback }=\frac{F C_{0}}{F C_{\text {média }}}
$$

Sendo:

$F C_{0}=$ Fluxo de caixa no período de tempo 0.

$F C_{\text {média }}=$ Fluxo de caixa médio por período de tempo.

\subsection{Taxa Mínima de Atratividade (TMA)}

Para um investimento ser considerado atrativo, deve render, no mínimo, a taxa de juros equivalente à rentabilidade das aplicações correntes consideradas sem risco. Esta taxa de juros geradora de rentabilidade sem riscos é, portanto, a taxa mínima de atratividade (TMA).

\subsection{Taxa Interna de Retorno (TIR)}

A Taxa Interna de Retorno (TIR) consiste em encontrar a remuneração percentual do investimento por ciclo. É uma taxa onde o Valor Presente Líquido (VPL) de um investimento é igual a zero, ou seja, é taxa que torna o valor presente dos fluxos de caixa igual ao 
investimento inicial realizado. Em outras palavras, é a taxa ideal para que o investimento não proporcione perdas ou ganhos.

A análise do resultado obtido pela TIR é associada à Taxa Mínima de Atratividade (TMA), pois o projeto escolhido é o que possuir a TIR maior que a TMA. Porém, caso a TIR disponha valor igual à TMA, a seleção do projeto é imparcial.

Matematicamente, a TIR é definida através de uma da equação abaixo.

$$
\sum_{t=1}^{n} \frac{F C_{t}}{(1+T I R)^{t}}-F C_{0}=0
$$

Sendo:

$F C_{t}=$ Fluxo de caixa no tempo $\mathrm{t} ;$

$F C_{0}=$ Fluxo de caixa no período de tempo 0.

$\mathrm{n}$ = quantidade total de períodos na linha de tempo do fluxo de caixa;

TIR = Taxa Interna de Retorno

Critérios utilizados ao avaliar o investimento pela TIR:

Se a TIR for maior que a TMA, deve-se aceitar o investimento;

Se a TIR for menor que a TMA, deve-se rejeitar o investimento.

\section{Metodologia}

Para realizar o Fluxo de Caixa da AppMais em relação ao Finances Happy foram analisadas algumas entradas de caixa de anos anteriores, assim como foram produzidas algumas previsões para os anos seguintes, de acordo com o seu desempenho até então, visto que o número de pessoas que deixam de pagar a mensalidade do app é sempre menor que o número de pessoas que passam a utilizá-lo. O ideal seria o valor das receitas aumentarem progressivamente. Todavia foi mantido o mesmo valor para a previsão das receitas seguintes, como foi orientado pelos sócios. O período de amortização do aplicativo é de 10 anos e houve 
uma previsão de entrada de caixa também para este intervalo de tempo, dados estipulados pela empresa. Já o custo de capital ficou em torno de $10 \%$ ao ano. Foi realizado uma pesquisa em relação ao imposto de renda aplicado em empresas de software e fica em torno de $7 \%$. $\mathrm{O}$ Investimento inicial para a realização do app ficou em torno de $\mathrm{R} \$=150000,00$. Os custos fixos foram calculados em relação à alguns dados, como: aluguel, salários dos funcionários, internet e energia, resultando em: $\mathrm{R} \$=33600,00$. Como o aplicativo amortiza completamente num período de 10 anos ele não possui valor residual. Com esses dados em mãos, e como havia a necessidade de saber a rentabilidade, o tempo de retorno do investimento e se estava gerando lucro, optou-se por utilizar o payback simples, descontado, o VPL e a TIR.

\section{Resultados e discussões}

O fluxo de caixa do projeto é o norteador para o estudo da viabilidade do investimento no aplicativo "Finances Happy", para a composição deste é necessário o lançamento das receitas e despesas do projeto. Nesta etapa é apresentada toda a composição dos valores das receitas, bem como sua distribuição ao longo do período de análise. A seguir há o esquema do fluxo de caixa do projeto de criação do aplicativo no período de dez anos.

Sendo assim os cálculos que norteiam o estudo da viabilidade econômica do investimento

Tabela 1 - Cálculo dos fluxos através das receitas e despesas

\begin{tabular}{|c|c|c|c|c|c|c|c|c|c|c|c|}
\hline & \multicolumn{11}{|c|}{ Ano } \\
\hline & 0 & 1 & 2 & 3 & 4 & 5 & 6 & 7 & 8 & 9 & 10 \\
\hline (+) Receitas & & 100000 & 100000 & 100000 & 100000 & 100000 & 100000 & 100000 & 100000 & 100000 & 100000 \\
\hline (-) CV e DV & & \begin{tabular}{|l|}
- \\
\end{tabular} & - & \begin{tabular}{|l|}
- \\
-
\end{tabular} & - & - & ( & - & \begin{tabular}{|l|}
- \\
-
\end{tabular} & - & - \\
\hline (-) CF e DF & & -33600 & -33600 & $\mid-33600$ & -33600 & -33600 & -33600 & -33600 & $\mid-33600$ & -33600 & -33600 \\
\hline (-) Amortização & & 15000 & 15000 & 15000 & 15000 & 15000 & 15000 & 15000 & 15000 & 15000 & 15000 \\
\hline (=)LAIR & & 51400 & 51400 & 51400 & 51400 & 51400 & 51400 & 51400 & 51400 & 51400 & 51400 \\
\hline (-) IR & & -5700 & -5700 & -5700 & -5700 & -5700 & -5700 & -5700 & -5700 & -5700 & -5700 \\
\hline (=) LLOPDIR & & 45700 & 45700 & 45700 & 45700 & 45700 & 45700 & 45700 & 45700 & 45700 & 45700 \\
\hline (+) Amortização & & 15000 & 15000 & 15000 & 15000 & 15000 & 15000 & 15000 & 15000 & 15000 & 15000 \\
\hline (=) FCOP & & 60700 & 60700 & 60700 & 60700 & 60700 & 60700 & 60700 & 60700 & 60700 & 60700 \\
\hline & & & & & & & & & & & \\
\hline Investimento na real. Do app & -150000 & & & & & & & & & & \\
\hline FC Livre & -150000 & 60700 & 60700 & 60700 & 60700 & 60700 & 60700 & 60700 & 60700 & 60700 & 60700 \\
\hline FC Cumulativo & & -89300 & -28600 & 32110 & 92810 & 153510 & 214210 & 274910 & 335620 & 396320 & 457020 \\
\hline VP DESCONTADO & & 55180 & 50160 & 45600 & 41460 & 37680 & 34260 & 31114 & 28310 & 25740 & 23400 \\
\hline & & $\mid-94820$ & -44600 & 1006 & 42520 & 80200 & 114460 & 145600 & 173910 & 199650 & 223050 \\
\hline
\end{tabular}

Fonte: Elaborada pelo autor 
O principal objetivo é avaliar a viabilidade da criação de um aplicativo. Os resultados descritos na imagem 01 a seguir nos mostram se o investimento é viável. Como podemos observar, os valores encontrados elucidam ótimos resultados. Até porque a TIR de 38,96 \% é superpositiva, visto que a taxa de atratividade fica em torno de $10 \%$, tendo um avanço de mais de 3 vezes o valor mínimo esperado. O VPL de 222975, 2 também evidencia ótimos resultados já que é um valor positivo e relativamente alto, bem maior que o investimento inicial de 150000. Sem deixar de mencionar o Payback que comprova um período de retorno do investimento bem discreto de 2,47 anos para o Payback Simples e de apenas 2,97 anos para o Payback Descontado em relação ao período de amortização, bem como o período de análise de fluxo de caixa do App. Dessa forma, pode-se perceber que além de lucrativo o aplicativo consegue retornar o valor do seu investimento inicial de maneira acelerada.

Figura 1 - Resultados obtidos através de análise financeira

\begin{tabular}{|c|c|}
\hline TMA & $\mathbf{0 , 1}$ \\
\hline PAYBACK SIMPLES & $\mathbf{2 , 4 7}$ \\
\hline VPL & 222975,2 \\
\hline PAYBACK DESCONTADO & 2,9793 \\
\hline TIR & 38,96 \\
\hline
\end{tabular}

Fonte: Elaborada pelo autor

\section{Conclusão}

Através da junção de conceitos oriundos da engenharia econômica, como análise de investimentos, e da modelagem, concluímos então que a aplicação de capital é viável, pois como foi possível observar ao longo desse estudo de caso, a taxa internar de retorno de $38,96 \%$ é maior que a taxa do custo de capital, certificando que é compensável conceder $10 \%$ tendo um retorno de $28,96 \%$. Além disso, o payback é de 2,47 anos, ou seja, é o um tempo consideravelmente baixo para um grande investimento que tem um retorno bem positivo. Percebe-se então que o desejo inicial da empresa de passar a aplicar maiores investimentos no aplicativo Finances Happy é eminentemente indicado, em virtude dos resultados encontrados extremamente positivos.

\section{Referências bibliográficas}


ANEEL - AGÊNCIA NACIONAL DE ENERGIA ELÉTRICA. Estudo de vida útil econômica e taxa de depreciação. Disponível em: < http://www2.aneel.gov.br/aplicacoes/audiencia/arquivo/2006/012/documento/relatorio_vida_util_volume_1.pdf> Acesso em 21 novembro de 2019.

ASSAF NETO, Alexandre. Finanças Corporativas e Valor. $7^{\circ}$ edição. Editora Atlas. 2014.

AVILA, Antônio Victoriano. Matemática Financeira e Engenharia Econômica / Antônio Victoriano Avila; Florianópolis. "Programa de Educação Tutorial da Engenharia de Civil - UFSC”, 2013.

ASSAF NETO, Alexandre. Mercado Financeiro. $2^{\circ}$ edição. Editora Atlas. 2001.

PORTAL DE CONTABILIDADE. Análise de Investimentos. Disponível em: < http://www.portaldecontabilidade.com.br/tematicas/analiseinvestimentos.htm> Acesso em 20 novembro de 2019.

SOFTLINE. As 04 principais ferramentas para a análise de investimentos. Disponível em: <https://brasil.softlinegroup.com/sobre-a-empresa/blog/as-4-principais-ferramentas-para-analise-deinvestimentos> Acesso em 21 novembro de 2019.

SOUZA, Acilon Batista. Projetos de Investimentos de Capital: Elaboração, Análise e Tomada de Decisão. $1^{\circ}$ edição. São Paulo: Editora Alves. 2003.

TAHA, P. Estudo de Viabilidade Econômico-Financeira da Produção de Surimi, Universidade Federal de Santa Catarina. Florianópolis: 1996. 